Images du travail, travail des images

5 | 2018

Le travail à l'écran : mise en scène des groupes professionnels par les médias

\title{
Séance de formation à la self-défense chez les
} gardiens de la paix

Jean-Michel Schlosser

\section{CpenEdition}

\section{Journals}

Édition électronique

URL : http://journals.openedition.org/itti/910

DOI : 10.4000/itti.910

\section{Éditeur}

Université de Poitiers

\section{Référence électronique}

Jean-Michel Schlosser, « Séance de formation à la self-défense chez les gardiens de la paix », Images du travail, travail des images [En ligne], 5 | 2018, mis en ligne le 01 février 2018, consulté le 14 avril 2021. URL : http://journals.openedition.org/itti/910 ; DOl : https://doi.org/10.4000/itti.910

Ce document a été généré automatiquement le 14 avril 2021

Images du travail, travail des images 


\title{
Séance de formation à la self- défense chez les gardiens de la paix
}

\author{
Jean-Michel Schlosser
}

Cours de self-défense aux élèves gardiens de la paix

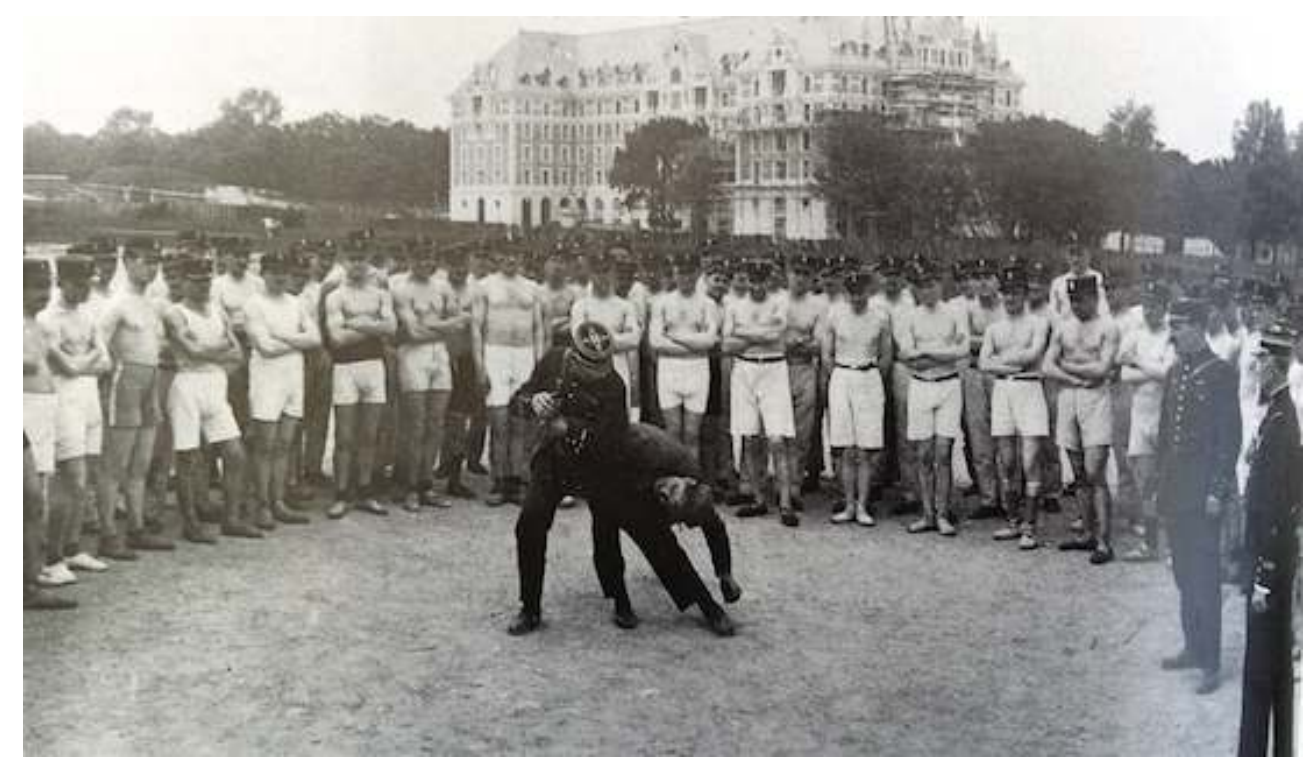

1 Cette photo, issue des archives de la Préfecture de police, illustre un cours de self-défense donné à des élèves gardiens de la paix en formation initiale dans le courant des années 1930, époque où seule la Préfecture de police de Paris avait instauré une formation pour ses policiers.

2 Elle constitue une partie d'un reportage photo où ce qui apparaît tout de suite comme image décalée repose sur la tenue des élèves. En tenue de sport, torses nus et shorts, les élèves portent cependant le képi comme forme transcendantale de leur identité. Le gardien de la paix sans son couvre-chef serait-il encore un gardien de la paix ? L'image est forte, le symbole puissant : même en " petite tenue ", l’État est là ! 
3 Le mouvement démontré, sans doute issu du Jiu-Jitsu, est intéressant pour l'époque quand on sait que les premiers experts d'arts-martiaux japonais introduisent ces pratiques en France à la toute fin des années 1950. Cette technique est présentée par un formateur en tenue d'uniforme, le képi à sa place malgré la dynamique du mouvement, ce qui représente une forme de simulation très proche de la réalité, la pratique aujourd'hui en kimono, pour reprendre l'expression triviale, aurait tendance au contraire à l'en éloigner.

Deux autres formateurs, également en uniforme, semblent superviser l'ensemble, le personnage le plus à droite sur la photographie porte des galons d'officier (Lieutenant), l'officier de paix responsable de la formation dont la présence est sans doute due au reportage.

5 On note la tenue adoptée par «l'agresseur», un moniteur participant à la démonstration, déguisé en apache pour l'occasion, permet de voir jusqu'où est poussé le réalisme, à moins qu'il ne soit habillé en ouvrier, participant à une forme secondaire d'inculcation des « classes laborieuses, classes dangereuses !»

6 Tous les stagiaires sont attentifs, la plupart ont les bras croisés, attente de la répétition ou perplexité devant la technique mise en œuvre. Figés dans une posture qui n'est pas un garde à vous, mais dont l'apparence laisse à penser que la décontraction n'est pas de rigueur au moment du cours. Tous les regards sont tournés vers l'exécutant, y compris ceux des observateurs gradés.

7 Découverte au cours de mes recherches dans le cadre de ma thèse sur la formation des policiers, cette photo, même si elle est sûrement posée, me donne l'impression d'une discipline dans la formation que l'on ne retrouve pas forcément aujourd'hui. Il y a sans doute aussi la curiosité vis-à-vis de ces techniques très innovantes, même la boxe française connaît ses premiers développements dans la formation des policiers à l'époque.

8 J'imagine alors les interrogations qui doivent parcourir les pensées des stagiaires: "Allons-nous réussir à pratiquer ce geste?", «Est-ce vraiment efficace dans la réalité ? ", « Aurons-nous un examen noté sur ces pratiques? ». Mais aussi, peut-être, la satisfaction d'apprendre quelque chose de nouveau et d'utile.

9 Il ne s'agit pas de se battre, mais bien d'opposer à la force brute un mouvement contrôlé, réfléchi et adapté. Le port du couvre-chef réglementaire vient sans doute rappeler aux élèves, futurs gardiens de la paix, leurs devoirs d'exemplarité. La norme est dans le geste comme elle est dans la tenue.

\section{AUTEUR}

\section{JEAN-MICHEL SCHLOSSER}

Après avoir exercé la profession d'officier de police pendant 35 ans, Jean-Michel Schlosser est actuellement doctorant en sociologie à l'URCA de Reims, Centre d'Études et de Recherches sur les 
Emplois et les Professionnalisations (CEREP EA 4692), sous la direction de Françoise Laot. En parallèle de sa thèse, intitulée « La formation des policiers en France de 1960 à nos jours. Impact et résonance des politiques publiques de sécurité sur les professionnalités policières en France de 1960 à aujourd'hui. », il poursuit un DU « Sécurité et Défense »

Il s'intéresse à la sociologie de la force publique, la sociologie de la violence et des comportements déviants, au rapport État-citoyens et à la philosophie politique. 